\title{
A common biomarker signature for tolerated allografts and self tissues
}

\author{
Alain Le Moine ${ }^{1 *}$ and Nick D. Jones ${ }^{2}$ \\ 1 Department of Nephrology Transplantation and Dialysis, Hopital Erasme, Institute for Medical Immunology, Université Libre de Bruxelles, Brussels, Belgium \\ 2 Transplantation Research Immunology Group, Nuffield Department of Surgical Sciences, John Radcliffe Hospital, University of Oxford, Oxford, UK \\ *Correspondence: alemoine@ulb.ac.be
}

\section{A commentary on}

Biomarkers of transplantation tolerance: more hopeful than helpful?

by Cobbold, S. P., Adams, E., and Waldmann, H. (2011). Front. Immun. 2:9. doi: 10.3389/ fimmu.2011.00009

For obvious reasons, there is an urgent need to define reliable biomarkers of transplantation tolerance that will allow better tailoring of immunosuppression and a safer withdrawal of immunosuppressive drugs. Simultaneously, this will make clinical trials of tolerance induction easier to perform and promote. However, to date there is no reliable means to discriminate between the absence of rejection due to the effects of conventional immunosuppression and the absence of rejection due to the successful induction of an active process of tolerance. Consequently, most clinicians administer a classical immunosuppressive protocol to their patients or prefer to include patients in clinical trials driven by pharmaceutical companies.

The problem is not easy. We already know from basic research performed with peripheral blood mononuclear cells (PBMCs) from the rare patients that are "by chance" tolerant to a kidney allograft or the more frequent tolerant liver transplant recipients, that putative biomarkers of operational tolerance (that remain to be validated in large prospective studies) are distinct for each organ (MartinezLlordella et al., 2008; Sagoo et al., 2010; Sanchez-Fueyo and Strom, 2011). This suggests that the underlying mechanisms are distinct too. In experimental transplantation models (small and large animals), the number of cells and the mechanisms involved in tolerance are numerous and are increasing (regulatory $\mathrm{T}$ cells, mast cells, myeloid derived suppressor cells, immune privilege, enzyme activity such as iNOS, arginase, heme oxygenase-1, NO, etc...;
Waldmann, 2010). If the success of experimental protocols of tolerance induction or its maintenance depends on those mechanisms, as demonstrated by specific models, they do not represent a biomarker as such. This is well illustrated by the example that regulatory $\mathrm{T}$ cells have been found to be present in tolerated but also rejected allografts. Beyond the scope of alloreactivity, the mechanisms implicated in tolerance to self antigens are still incompletely understood. Therefore, it looks tricky to define a promising strategy for identifying universal biomarkers of tolerance. Besides, the potential effects of immunosuppressive drugs on those tolerogenic mechanisms further complicate the problem.

In the present issue, Cobbold et al. (2011) chose an elegant and sophisticated experimental alternative to overwhelm these difficulties (ref). They compared gene profile expression in draining lymph nodes, spleen, and transplanted tissue of three apparently different immunological situations: skin allograft tolerance, skin allograft rejection, and syngeneic transplants. To ensure that observations were robust and unbiased, the allogeneic situation included transplantation across multiple minor antigen disparities, minor plus major (full mismatch) or in the presence of graft-reactive, monospecific TCR transgenic T cells. This confirmed that multiple innate and adaptive mechanisms are recruited in reliable forms of tolerance and operate within the graft, not systematically, strongly suggesting that fishing for surrogate markers of tolerance in patients should be performed with grafted tissue (or perhaps by-products) rather than PBMCs.

At least, two other important messages are contained in this manuscript. First, foxp3 mRNA is definitely not a biomarker of tolerance as such, and the fate of allograft depends on the balance between "regulatory-associated" genes and effector genes. The second important message is that tolerated allografts behave like syngeneic transplants. So far, this gold standard syngeneic control is of course missing in clinical transplantation research although this might provide some keys in the understanding of mechanisms involved in transplantation tolerance. Perhaps, further clinical research addressing specific biomarkers of tolerance should include experimental equivalent of the syngeneic transplants reported here as suggested by this nice study.

\section{REFERENCES}

Cobbold, S. P., Adams, E., and Waldmann, H. (2011) Biomarkers of transplantation tolerance: more hopeful than helpful? Front. Immun. 2:9. doi: 10.3389/ fimmu.2011.00009

Martinez-Llordella, M., Lozano, J. J., Puig-Pey, I., Orlando, G., Tisone, G., Lerut, J., Benitez, C., Pons, J. A., Parrilla, P., Ramirez, P., Bruguera, M., Rimola, A., and SanchezFueyo, A. (2008). Using transcriptional profiling to develop a diagnostic test of operational tolerance in liver transplant recipients. J. Clin. Invest. 118, 2845-2857. Sagoo, P., Perucha, E., Sawitzki, B., Tomiuk, S., Stephens, D. A., Miqueu, P., Chapman, S., Craciun, L., Sergeant, R., Brouard, S., Rovis, F., Jimenez, E., Ballow, A., Giral, M., Rebollo-Mesa, I., Le Moine, A., Braudeau, C., Hilton, R., Gerstmayer, B., Bourcier, K., Sharif, A., Krajewska, M., Lord, G. M., Roberts, I., Goldman, M., Wood, K. J., Newell, K., Seyfert-Margolis, V., Warrens, A. N., Janssen, U., Volk, H. D., Soulillou, J. P., Hernandez-Fuentes, M. P., and Lechler, R. I. (2010). Development of a cross-platform biomarker signature to detect renal transplant tolerance in humans. J. Clin. Invest. 120, 1848-1861.

Sanchez-Fueyo, A., and Strom, T. B. (2011). Immunologic basis of graft rejection and tolerance following transplantation of liver or other solid organs. Gastroenterology 140, 51-64.

Waldmann, H. (2010). Tolerance: an overview and perspectives. Nat. Rev. Nephrol. 6, 569-576.

Received: 11 April 2011; accepted: 18 April 2011; published online: 04 May 2011.

Citation: Moine AL and Jones ND (2011) A common biomarker signature for tolerated allografts and self tissues. Front. Immun. 2:11. doi: 10.3389/fimmu.2011.00011 This article was submitted to Frontiers in Immunological Tolerance, a specialty of Frontiers in Immunology.

Copyright (c) 2011 Moine and Jones. This is an openaccess article subject to a non-exclusive license between the authors and Frontiers Media SA, which permits use, distribution and reproduction in other forums, provided the original authors and source are credited and other Frontiers conditions are complied with. 